\title{
7-Nitro Indazole, a Selective Neuronal Nitric Oxide Synthase Inhibitor in Vivo, Impairs Spatial Learning in the Rat
}

\author{
Michael J. Rowan ${ }^{1}$ \\ ${ }^{1}$ Department of Pharmacology and Therapeutics and \\ ${ }^{2}$ Department of Physiology \\ Trinity College \\ Dublin 2, Republic of Ireland
}

Christian Hölscher, ${ }^{1,3}$ Liam McGlinchey, ${ }^{1}$ Roger Anwyl, ${ }^{2}$ and

\section{Abstract}

Nitric oxide (NO) is an intercellular messenger that has been suggested to have a role in learning and memory formation. Previous studies with nonselective NO synthase inhibitors have produced contradictory results in learning experiments. However, these drugs also produced blood pressure changes, as NO is an endothelial-derived relaxing factor. $A$ novel NO synthase inhibitor, 7-nitro indazole (7-NI), as a dose (30 $\mathrm{mg} / \mathrm{kg}$ i.p.) shown previously to inhibit neuronal NO synthase by $85 \%$ without affecting blood pressure, produced amnesic effects both in a water maze and in an 8-arm radial maze. Latency as well as distance was greater in the 7-NI group in the water maze while swim speed was not affected. Latency, working memory (WM), and reference memory (RF) errors were also higher in the 7-NI group in the 8-arm maze. At the end of the second training day, these differences were no longer apparent. However, on the fourth training day, a transfer test in the water maze showed that 7-NI had produced a spatial memory deficit, reducing quadrant bias and the number of annulus crossings. Learning of a visual cue task was not affected. No difference between groups was visible in an open field test. We conclude that neuronal NO sythase activity plays a role in learning and memory formation in the rat.

\footnotetext{
${ }^{3}$ Corresponding author.
}

\section{Introduction}

Nitric oxide (NO) is an intercellular messenger that plays a role in many physiological systems. In the nervous system, NO acts as a neurotransmitter (Amir 1992). The enzyme NO synthase (NOS) has been found in neurons (Bredt and Snyder 1992; Vincent and Kimura 1992), and endogenous NO production occurs in neuronal cultures (Ma et al. 1991). At least three isoforms of NOS have been identified. NOS isoform $I$ is found in neurons, whereas isoform III has been purified from endothelial cells (Schmidt et al. 1992). Both isoforms are $\mathrm{Ca}^{2+}$ dependent (Moncada and Palmer 1992). Isoform type II is inducible and $\mathrm{Ca}^{2+}$ independent. It is found in most tissues of the body (Kilbourn 1991; Nathan 1991). NO has been suggested to act as a retrograde messenger (O'Dell et al. 1991; Schuman and Madison 1991), modulating up-regulation of transmitter release, which would result in long-term potentiation (LTP) of synaptic transmission, a phenomenon that has been suggested to be the neuronal basis of memory formation (for discussion, see Bliss and Collingridge 1993). Early investigations claim that NO is an essential messenger in LTP induction. Inhibition of NO synthesis prevented induction of LTP in the CA1 field of rat hippocampal slices (Böhme et al. 1991; Bon et al. 1992; Musleh et al. 1993), or in a cortical slice preparation (Nowicky and Bindman 1993). These positive results were soon followed by reports that the block of LTP was found only under defined conditions (see, e.g., Williams et al. 1993).

Measuring LTP formation in vivo did not clarify the confusion. Although some research groups found block or impairment of induction of LTP, others did not. In one study the NOS inhibitor

LEARNING \& MEMORY 2:267-278 @ 1995 by Cold Spring Harbor Laboratory Press ISSN1072-0502/96 $\$ 5.00$

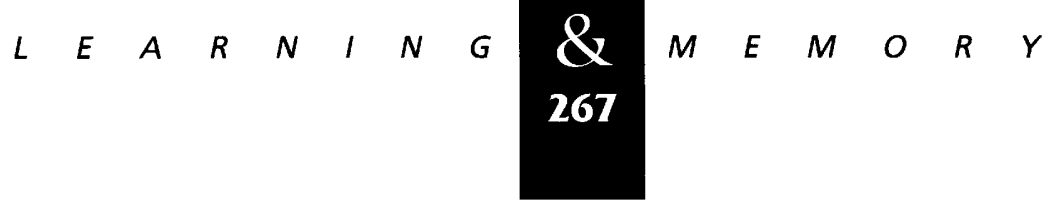


$N$-nitro-L-arginine-methyl-ester (L-NAME) prevented LTP induction in vivo in the rat (Iga et al. 1993; Mizutani et al. 1993), whereas in another study, LTP induction was not affected (Bannerman et al. 1994b) or only LTP of the population spike was inhibited (Bannerman et al. 1994c). A third study found that L-NAME raised the threshold for the induction of LTP (P.F. Chapman, pers. comm.).

As LTP is assumed to represent a cellular process of memory formation, the question arose whether NO plays a role in learning and memory. Several studies were conducted involving learning a spatial task in a radial maze or in a water maze as well as learning nonspatial tasks. Learning tasks in the radial arm maze and of a social recognition olfactory task were inhibited, whereas shockavoidance learning was unaffected after injection of the NOS inhibitor nitro-l-arginine (L-NARG) (Böhme et al. 1993). L-NAME produced learning impairments of a place-navigation task (Estall et al. 1993). Learning a passive avoidance trial in chicks was impaired following L-NARG injection (Hölscher and Rose 1992, 1993). Chapman et al. (1992) tested the effect of L-NAME on rats learning a water maze task and on rabbits learning a conditioned eye-blink response and found that both forms of learning are impaired by the drug. Bannerman et al. (1994a), however, further tested the effect on L-NAME on rats learning a water maze and found that though spatial learning was impaired, the learning of a visual discrimination task involving two visible platforms was not affected, but analysis of the early training trials of the visual discrimination task revealed significantly elevated escape latencies in the L-NAME-treated rats. The interpretation was that NOS inhibition might cause more general impairments. Also, training animals on a one-trial-per-day basis showed that L-NAME-injected rats had no difficulty learning the task. Furthermore, after learning the task in one water maze, L-NAME-injected rats had no effect on relearning the task in a second water maze with a novel spatial environment. Bannerman et al. (1994a) therefore concluded that the impairment caused by L-NAME is not attributable to a specific spatial learning impairment.

All of the in vivo studies mentioned suffer from one great drawback. The drugs used are not specific for the neuronal isoform of NOS and greatly affect blood vessel diameter and blood pressure (Rees et al. 1990; Snyder and Bredt 1992; Lot et al. 1993). Furthermore, L-NAME is known to antagonize muscarinic acetylcholine receptors
(Buxton et al. 1993). Because learning, as well as motor activity, is dependent on cholinergic transmission (Ohno et al. 1994), L-NAME could have various other effects than spatial learning on rat performance, as Bannerman et al. presumed from their studies.

To avoid these undesired effects, we tested the novel selective neuronal NOS inhibitor 7-nitro indazole (7-NI) on spatial and nonspatial learning of rats in a radial arm maze and in the water maze. This drug has been shown to be specific for NOS in vivo (Babbedge et al. 1993; Moore et al. 1993a) without affecting endothelial NOS. 7-NI has no effect on mean arterial pressure at doses ranging from 20 to $80 \mathrm{mg} / \mathrm{kg}$ i.p. (Moore et al. 1993a,b). Infected interperitoneally, $30 \mathrm{mg} / \mathrm{kg}$ of $7-\mathrm{NI}$ inhibited NOS in various brain areas including the hippocampus $30 \mathrm{~min}$ after injection by $85 \%, 2 \mathrm{hr}$ later by $80 \%$, and $4 \mathrm{hr}$ later by $55 \%$ (MacKenzie et al. 1994). Furthermore, recent experiments in our laboratory showed an effect of 7-NI on LTP induction at this dose. Injecting $30 \mathrm{mg} / \mathrm{kg}$ of $7-\mathrm{NI}$ i.p. in the anesthetized rat prevented the induction of LTP and the depotentiation of established LTP by low frequency stimulation. Injecting L-arginine together with 7-NI prevented these effects (Doyle et al. 1996). In a previous study $7-\mathrm{NI}$ proved to have amnesic effects in a one-trial passive avoidance task of the chick (Hölscher 1995).

Apart from learning tasks in the water maze we chose to test the effects of 7-NI in the radial arm maze as well. If the hypothesis by Bannerman et al. (1994a) holds that inhibition of NOS causes more general impairments not directly attributed to spatial learning impairment, latency but not numbers of errors should differ between 7-NI and the control group.

\section{Materials and Methods}

MATERIALS

DRUGS

7-NI was obtained form Biomol (Plymouth Meeting, Pennsylvania) and emulsified in warm sesame oil (Tesco, UK) by sonication for $5 \mathrm{~min}$. Rats were injected i.p. $9 \mathrm{mg}$ of 7-NI emulsified in $0.2 \mathrm{ml}$ of oil, which results in a concentration of 30 $\mathrm{mg} / \mathrm{kg} \pm 8 \%$. Control animals only received $0.2 \mathrm{ml}$ of sesame oil. All injections were carried out 30 min pretraining.

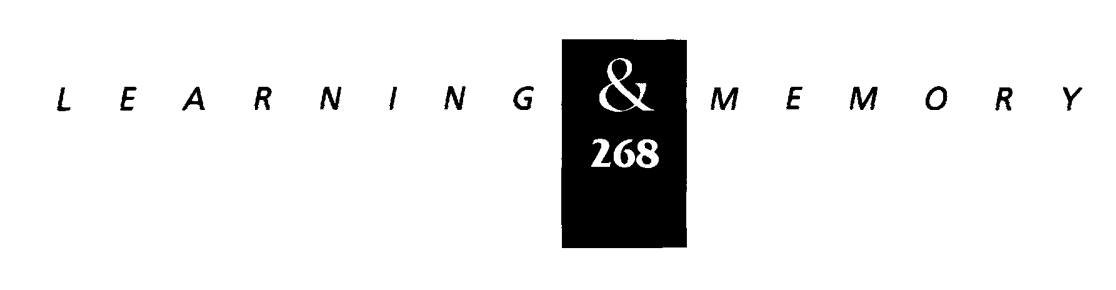


ANIMALS

Thirty-two male Wistar rats weighing between 280 and 320 grams were divided into four groups $(n=8$ each $)$. One control group and one test group were used for the water maze test and fed ad lib. The other two groups were tested in the radial arm maze and received a diet of 12 grams per day, which kept their weight at $\sim 85 \%$ of their free-feeding weight. Animals were held in opaque plastic cages, one group per cage, in a $23^{\circ} \mathrm{C}$ room with a light/darkness cycle from $8 \mathrm{AM}$ to $8 \mathrm{PM}$. All experiments were conducted according to and with permission of the Department of Health, Ireland.

OPEN FIELD

The open field is made of plywood, painted white. The width is $60 \mathrm{~cm}$; the walls are $35 \mathrm{~cm}$ high. The bottom is divided by red lines into 25 squares; four holes of $4 \mathrm{~cm}$ diameter are in the bottom, which can be investigated by the rats.

Each rat was put into the open field for $3 \mathrm{~min}$. Line crossings, rearing, grooming, head dips into the holes, and feces dropped was recorded.

\section{WATER MAZE}

The pool for the maze is made of Fiberglas and is painted white. Diameter is $120 \mathrm{~cm}$, height, 48 $\mathrm{cm}$, depth of water, $34 \mathrm{~cm}$ ( $26 \mathrm{~cm}$ with the platform exposed in the visual cue/discrimination task). The platform has a diameter of $10 \mathrm{~cm}$ and is $4 \mathrm{~cm}$ below the water surface in the water maze training and $4 \mathrm{~cm}$ above water level in the visual discrimination task. The water was kept at $22 \pm 2{ }^{\circ} \mathrm{C}$ and made opaque with titanium dioxide. The pool is situated in a room with visual cues such as a door, a curtain, a black cover over a window, and a water heater on the wall. The animals' movements were recorded with a video camera attached to the ceiling. Data were analyzed using a tracking program written by James Mahon (Vision Research Lab, Trinity College). The program measures latency of animals reaching the platform, path length, percent distance swum within the area $10 \mathrm{~cm}$ away from the wall (thigmotazis), and during the transfer task, percent distance swum in four quadrants into which the pool was divided by the tracking program, and the number of crossings of a $20-\mathrm{cm}$-diam. area where the platform was dur- ing the training period (annulus crossings). Animals' heads were marked with a black water-resistant felt tip marker to enable the program to track the white rats in the white water.

\section{TRAINING PROTOCOL}

DAYS 1 AND 2

On all 4 days, rats were injected i.p. with 30 $\mathrm{mg} / \mathrm{kg}$ of $7-\mathrm{NI}$ in $0.2 \mathrm{ml}$ of sesame oil or vehicle 30 min before their first trial. Animals were put in the water from one of four different starting points, which alternated clockwise. Each animal had six trials per day. The intertrial delay was $\sim 5 \mathrm{~min}$. Cutoff time for a trial was $120 \mathrm{sec}$ if the animal did not find the platform. Then, the animal was moved manually onto the platform and left there for 10 sec.

DAYS 3 AND 4, REVERSAL LEARNING

On day 3, the platform was moved from the NW quadrant to the SE quadrant. The animals had to perform the six trials on day 3 and two trials on day 4.

Time needed to find the platform was measured (latency), and the distance swum in the maze, as well as thigmotaxis (percent distance swum in the area $10 \mathrm{~cm}$ away from the wall).

\section{TRANSFER TEST}

On day 4 , the platform was removed after two training trials, and the animal was given $60 \mathrm{sec}$ in the pool. The percentage of distance swum in the four quadrants and annulus crossings made in the $2 \mathrm{~min}$ were measured. The annulus is a defined area by the tracking program located where the platform was located previously. It covers a circle $20 \mathrm{~cm}$ in diameter.

\section{VISUAL CUE TASK}

To test visual discrimination of animals, rats were infected with 7 -NI or vehicle $30 \mathrm{~min}$ before the task and given three trials in the pool with the platform $4 \mathrm{~cm}$ exposed above water level. Time and distance swum were recorded.

\section{8-ARM MAZE}

The maze is made of 15 -mm-thick white plastic-coated chip board and consists of 8 arms, each

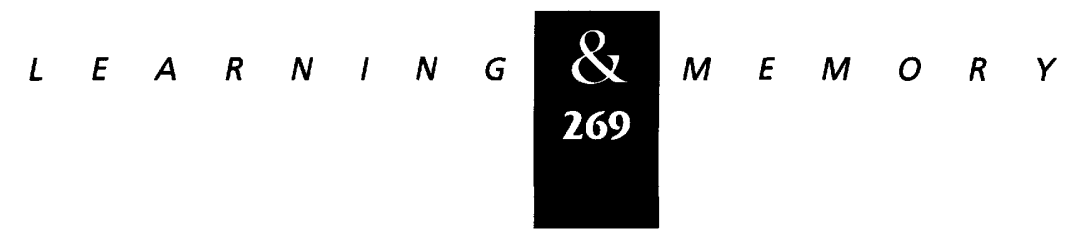


$19 \mathrm{~cm}$ wide, $60 \mathrm{~cm}$ long, and $30 \mathrm{~cm}$ high, and a central octagonal platform that is $46 \mathrm{~cm}$ in diameter. At the end of each arm, a white plastic weighing boat, $5 \mathrm{~cm}$ wide, was attached. In this, a Coco Pop (Kellogs) was placed if the arm was baited. The animals were not able to see the Coco Pop from the center platform. The animals were observed with a video camera from another room. The monitor was marked to allocate each arm a number from 1 to 8 .

\section{REINFORCED ALTERNATION}

Animals were put into the center of the platform. All arms were baited. The visits of each arm were recorded. The trial was terminated when the animal had visited all arms. The time required to find all pellets was recorded. Animals were injected i.p. with 7-NI ( $30 \mathrm{mg} / \mathrm{kg})$ or with vehicle 30 min before the animal started the trial.

TRAINING SESSIONS

DAYS 1 AND 2

Three arms were baited (arms 1, 2, 5). Animals were injected with $7-\mathrm{NI}(30 \mathrm{mg} / \mathrm{kg})$ or vehicle i.p. before their first trial. Each trial consisted of putting the animal into the center of the platform. The latency for retrieving all three pellets was measured, and visits of the different arms were recorded. Cutoff time for the trial was $5 \mathrm{~min}$ in which the animal had to find the pellets. Six trials were given per animal per day. The intertrial delay was $\sim 6 \mathrm{~min}$.

DAYS 3 AND 4 , REVERSAL LEARNING

Baited arms were changed on day 3 (arms 3, 7, 8). Animals were trained for 2 days with six trials each.

Data were analyzed for reference memory errors $(\mathrm{RF})$, which were entries into arms that were never baited, and for working memory errors (WM), which were entries into arms that had been visited by the rat within the same trial before.

\section{STATISTICS}

Results were analyzed with two-way repeated measure ANOVA using a computer program
(SYSTAT). The normality of data distribution was estimated before the ANOVA. Transformation of data to ensure equal distribution was not necessary.

The open field results, as well as the annulus crossing in the transfer test, was analyzed using an unpaired Student's $t$-test (two tailed). The normality of distribution of data was estimated, and transformation of data to ensure equal distribution was not necessary.

The data from the quadrant analysis of the transfer test were converted by angular transformation. Because data expressed in percent might not be distributed equally because of ceiling and bottom limit effects, data were transformed from $x$ to arcsin [square root $(x)$ ] to ensure equal distribution (for details see McNaughton 1993). A oneway ANOVA with a post hoc Tukey $t$-test was used to assess differences. Values are presented as the mean \pm s.E.M.

\section{Results}

\section{OPEN FIELD}

As Figure 1 shows, no difference between animals can be seen in any of the five measures. Motor activity of animals (line crossing, rearing) did not appear to be affected by 7-NI. Also, exploratory behavior (head dips, rearing) was not changed. Stress levels induced by the novel environment appeared to be the same for both groups,

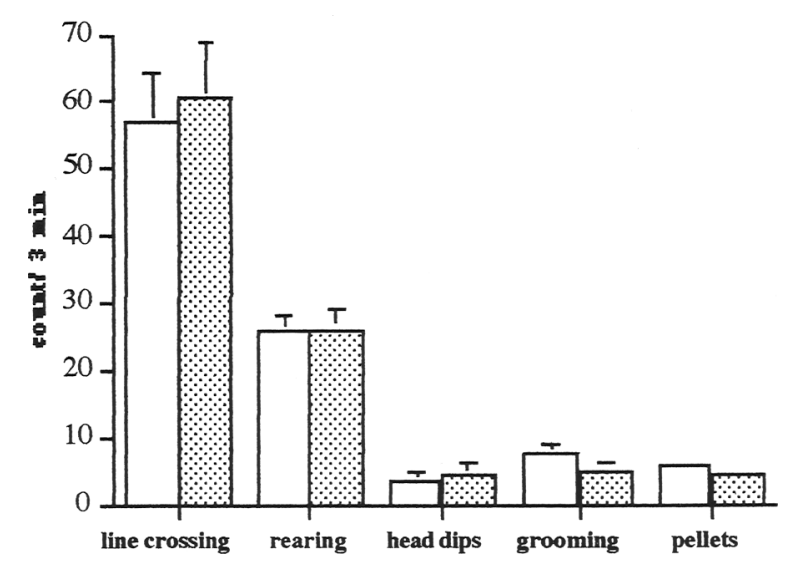

Figure 1: Results of open field assessment of the effect of animals injected with $7-\mathrm{NI}(30 \mathrm{mg} / \mathrm{kg}$ ) i.p., $30 \mathrm{~min}$ before trial $(n=8)$, (open bars) compared to controls $(n=8)$ injected with vehicle (stippled bars). No difference was visible in a $t$-test.

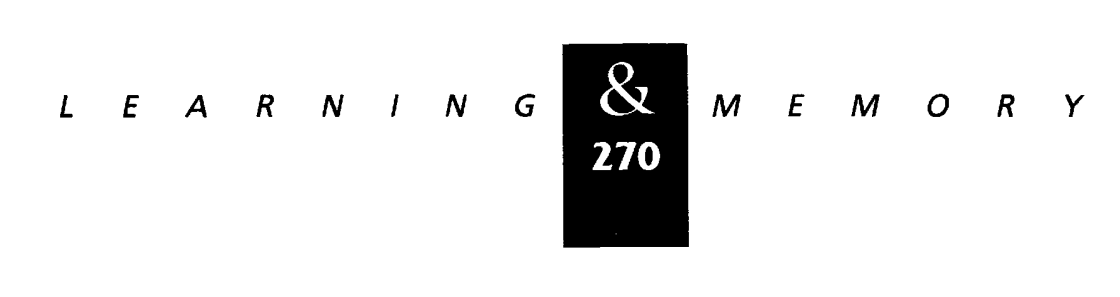


as the amount of fecal pellets dropped was the same.

\section{WATER MAZE}

7-NI has an effect on acquisition of a spatial water maze task. Figure $2 a$ shows that the latency of animals to reach the hidden platform was higher in the 7-NI group compared to controls in the first 2 days. Both groups learned over the course of 12 trials, as ANOVA revealed. The difference between groups disappeared in the next 2 days, despite the fact that the platform location had been changed. A nonsignificant trend of 7-NI animals needing more time for the task is visible for the first three trials after the change of platform location.

When analyzing the distance swum by animals over all trials we find a similar pattern (Fig. 2b). The drug group swam a longer distance in total to find the platform than the control group in the trial in which the drug animals needed more time to find the platform. Changing the platform location at day 3 affected animals only slightly. Again, the distance swum by animals decreased over trials.

No difference for swim speed between groups was seen on any day. Learning the task or injecting the drug did not influence the swim speed of animals (Fig. 2c).

The percent distance swum in the area $10 \mathrm{~cm}$ away from the wall (thigmotaxis) was different between groups. Rats injected with 7-NI spent more time near the pool wall for the first 2 days. The difference disappeared during the next 2 days (Fig. 2d).

\section{TRANSFER TASK}

In the transfer task, animals injected with vehicle crossed the annulus more often than animals injected with 7-NI. Speed and distance swum by animals was not different (data not shown). When analyzing the percent time spent in the four quadrants, a difference was seen between groups. The overall distance swum in the SE quadrant, where the platform had been located before, was lower in the 7-NI-treated rats. Those animals swam almost the same distance in each quadrant (Fig. 3a). Two average tracks drawn by the tracking program show that 7-NI-injected animals swam more or less evenly in the pool while control animals tended to stay within the area where the platform was located previously.

\section{VISUAL PLATFORM TASK}

No difference in latency, distance, or speed was seen in a task in which the platform was exposed and visible to the animals. Both groups learned to escape the water within three trials (Fig. 4).

EINFORCED ALTERNATION, ALL ARMS BAITED

There was no difference in time (7-NI: 245 sec \pm 28.6 s.E.M./control: 205 sec \pm 26.9 s.e.M) or number of working memory errors made (7-NI: $7 \pm 1.48$ s.E.M./control: $5.3 \pm 0.82$ s.E.M.) between groups when retrieving all food pellets from the arms (Student's $t$-test). The 7-NI group tended not to perform as well as controls.

THREE BAITED ARMS SPATIAL TASK

More time was needed by animals injected with 7-NI to retrieve food pellets in three baited arms compared to controls in the first 2 days as estimated by ANOVA (Fig. 5a). After changing the baited arms on day 3 a nonsignificant difference between groups appeared (see especially trials 2 and 3 ). From the fourth trial on, no difference between groups was visible.

Animals injected with 7-NI made more WM errors (visits or arms twice within one trial) than controls (Fig. 5b). This difference disappeared after trial 6. After changing the baited arms, a tendency was seen for 7-NI-injected animals to make more WM errors.

The amount of RF errors (visits of arms that were never baited) made in the first 2 days was higher in animals injected with 7-NI (Fig. 5c). This difference disappeared from trial 7 on; changing the arms on day 3 produced a nonsignificant trend toward 7-NI animals making more RF errors.

\section{Discussion}

7-NI ( $30 \mathrm{mg} / \mathrm{kg}$ ) appeared to have no general effect on motor activity, orientation, motivation, stress level, or visual discrimination, as is shown by the results of the open field test (Fig. 1), the speed measurements of animals in the water maze (Fig. 2c), and the visible platform task (Fig. 4). As the dose used in these studies is relatively low, no major impairment was expected, but because NOS is expressed in basal ganglia, the cerebellum, and in some nuclei in the basal brain (Vincent and

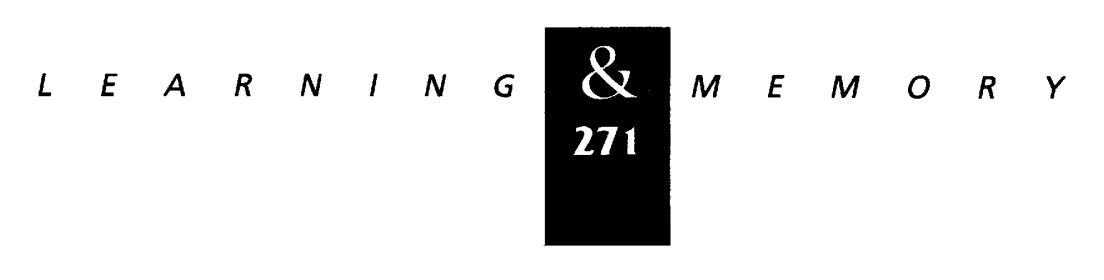


Downloaded from learnmem.cshlp.org on April 26, 2023 - Published by Cold Spring Harbor Laboratory Press Hölscher et al.
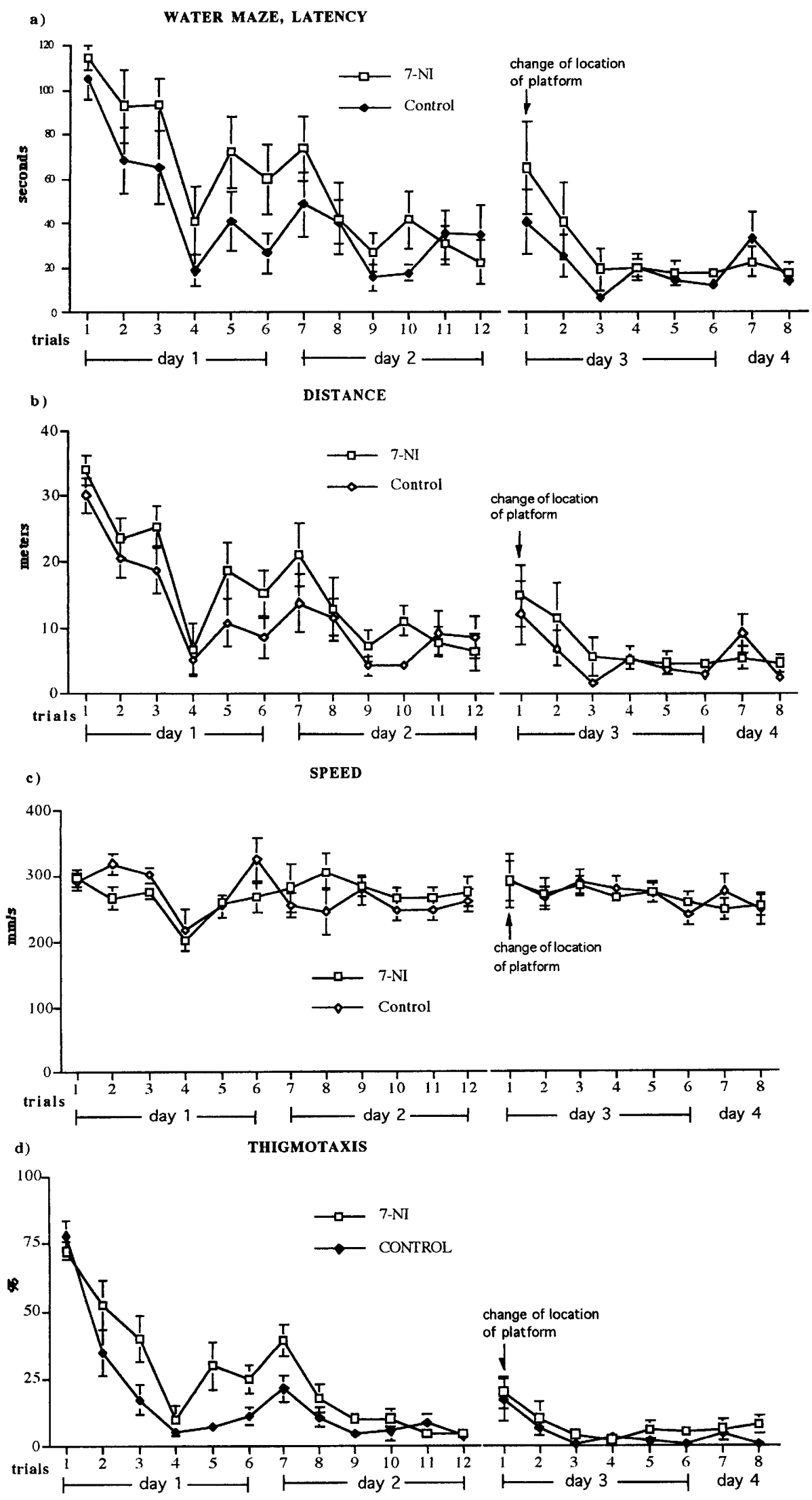

Figure 2: (See facing page for legend.)

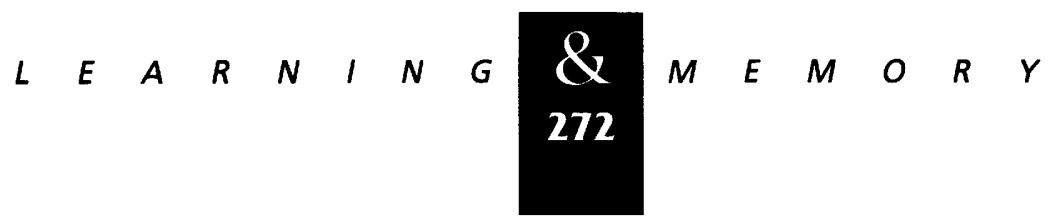


Kimura 1992) some impairment of motor skills or other effects not related to learning might have been observed. In the visible platform task, 7-NIinjected rats performed comparable to vehicle-injected rats (Fig. 4).

It is noteworthy that Bannerman et al. (1994a) found a difference in latencies of the first trials after injection of L-NAME in a visual discrimination task with two visible platforms. Because L-NAME-injected animals did not make more errors in choosing the right platform, the investigators suggest that the longer latency L-NAME-injected rats had in finding the submerged platform in the spatial water maze task can be explained by a general impairment in the first trials, which is not directly related to spatial learning. The observed impairment could be attributable to the effect of L-NAME on muscarinic receptors, which might compromise hippocampal activity, motor skills, and motor activity in rats.

Because no such nonspecific impairment can be observed in our study, the differences in latency in the spatial water maze task clearly point toward an impairment in spatial learning in the 7-NI-injected rats. This is not attributable to different swim speeds as Figure 2c shows, and latencies when learning the visible platform task were affected only to a very small degree (Fig. 4). However, as thigmotaxis is higher in the 7-NI group, it is possible that the drug group was slower in learning the water maze task because it needed more time to switch from a thigmotaxis strategy to a spatial orientation and search strategy. The result could be interpreted as a tendency to swim to the wall of the pool to look for a possiblity to escape rather than remembering the position of the platform. Naive animals tend to show higher percentages of thigmotaxis until they learn that the only escape route is via the platform some distance away from the wall of the pool. The results of the transfer task suggest further that 7-NI-injected an- imals do not seem to learn the location of the platform as well as controls.

This last result may appear a bit surprising, because the escape latencies of animals in the last training trials before the transfer task do not show a difference between groups and both groups learned the task equally well. It seems that the transfer task is a more sensitive test for memory retention than the acquisition trials. 7-NI-treated rats do seem to know the location of the platform is but not as well as control animals do. When looking for the platform, the 7-NI group is not as precise as the control group, an effect that is masked in the acquisition trials because once they find the platform, the trial is terminated. The same observation was made previously in studies in which drugs did not affect acquisition of a water maze task but affected performance in the transfer test (Hölscher et al. 1995).

The results of the water maze are supported by the radial arm maze results. Clearly, the 7-NI group made more WM and more RF errors than controls. As WM errors in this task are an indication of hippocampal functional impairment (Olton et al. 1979; Jarrard 1986), we suggest that the effects of 7-NI are linked to learning and memory consolidation and, at least in part, impairment of the entorhinal-hippocampal-septal system. Changing the location of the platform or the baited arms had only a small effect on both groups. Because reversal tasks are sensitive tests for hippocampal impairment (Jarrard 1986; Rasmussen et al. 1989), one would expect a larger impairment than seen in the results. Also, it is surprising that the initial learning impairment disappears after the first 2 days. This might be attributable to the fact that neurons can express endothelial NOS (Dinerman et al. 1994; O'Dell et al. 1994), and a block of neuronal NOS has only a limited effect. Furthermore, a $\mathrm{Ca}^{2+}$-dependent isoform of NOS can be induced in neurons (Kato et al. 1994; Minc-

Figure 2: (a) Latency of animals, injected with $7-\mathrm{NI}(30 \mathrm{mg} / \mathrm{kg})(n=8)$ i.p., $30 \mathrm{~min}$ before first trial compared to control $(n=8)$ injected with vehicle, finding a hidden platform in the water maze. On day 3 , the platform location was changed. Two-way ANOVA for days 1 and 2 revealed a difference between trials $[F(11,168)=33.23, P<0.0001]$ and treatment $[F(1,14)=8.94, P<0.003]$. Days 3 and 4 were not significant in their difference between treatments. (b) Distance swum by animals in the task. Two-way ANOVA for days 1 and 2 revealed a difference between trials $[F(11,168)=11.52$, $P<0.0001]$, and treatment $[F(1,14)=7.22, P<0.008]$. Days 3 and 4 were not significant in their difference between treatments. The difference between trials was $F(7,112)=3.66, P<0.001]$. (c) Speed of animals in the task. Two-way ANOVA did not show a difference between groups. (d) Thigmotaxis of animals in the task. Two-way ANOVA for days 1 and 2 revealed a difference between trials $[F(11,168)=33.23, P<0.0001]$, and treatment $[F(1,14)=16.93, P<0.0001]$. Days 3 and 4 were not significant in their difference between treatments. The difference between trials was $[F(7,112)=3.85, P<0.001]$.

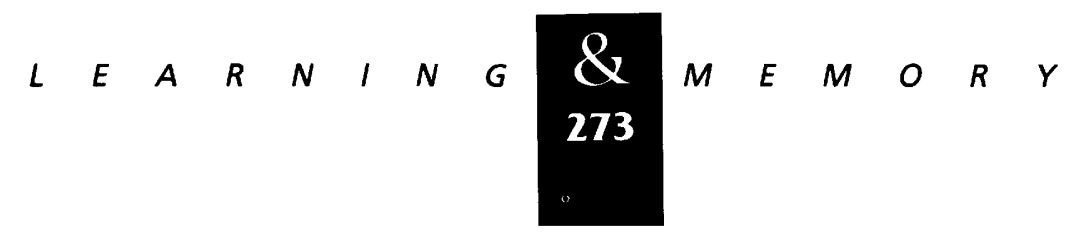


a

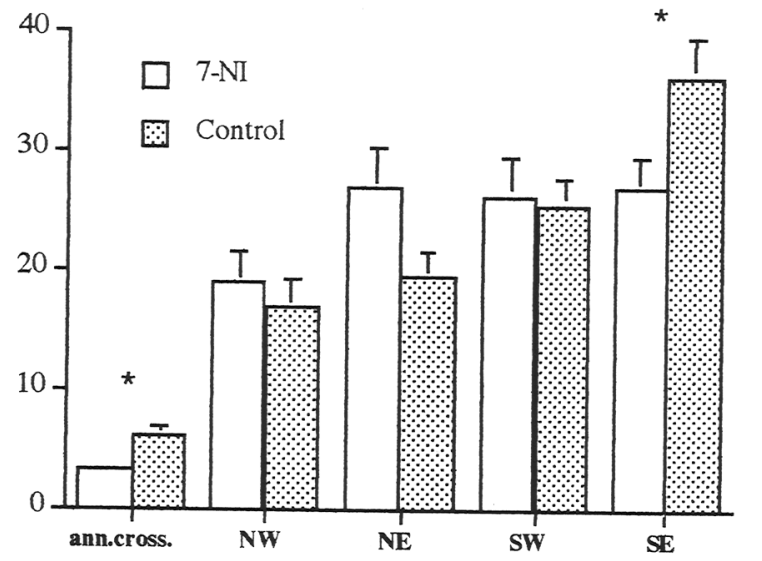

b
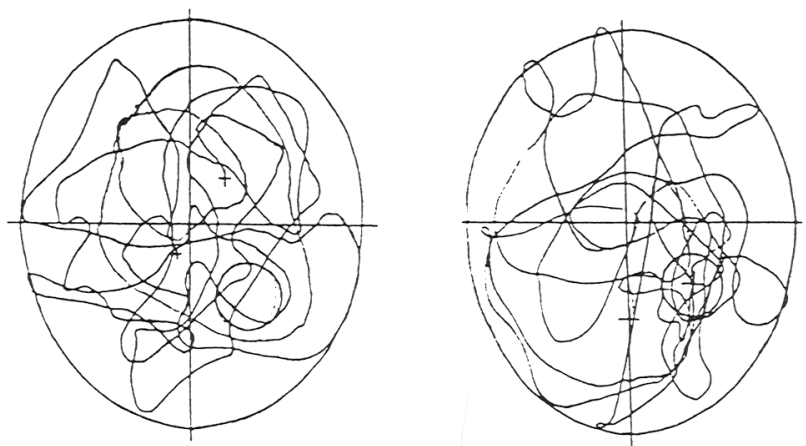

Figure 3: (a) Transfer task of animals, injected with 7-NI (30 mg/kg) i.p., before test compared to controls injected with vehicle after learning the position of the platform. The platform was removed, and each animal had $60 \mathrm{sec}$ in the pool. Annulus crossings: DF 14, $t=2.83, P<0.01$. Distance swum by animals was divided in quadrants. The location of the platform was in quadrant SE. One-way ANOVA with a post hoc Tukey $t$-test showed a significant difference between groups in the percentage distance swum in the SE quadrant. ANOVA $[F(14,64)=4.24, P<0.001] . t$-test SE:DF 14, $t=2.10$, $P<0.05$. (b) Representative tracks swum by animals injected with $7-\mathrm{NI}$ ( $30 \mathrm{mg} / \mathrm{kg}$ i.p., left) or with vehicle (right) during the transfer task. The circle marks the area where the platform was located previously. Crossing of the circle was counted as an annulus crossing by the tracking program. The $7-\mathrm{NI}$-injected animal spent $24 \%$ time in the target quadrant, the control animal, $36 \%$.

Golomb and Schwartz 1994; Saxon and Beitz 1994). An increased expression of NOS could mean that not all enzyme is blocked by the drug. However, measuring NOS activity after chronic inhibition by L-NAME still showed a reduction in activity of $95 \%$ (Bannerman et al. 1994a).

A different interpretation is that the system of neuronal transmission on which learning is based adapts to the block and compensates the lack of one transmitter with the increased production of a transmitter that plays a similar role. It has been suggested that NO acts as a retrograde messenger that modulates increased transmitter release after postsynaptic activation to enhance transmission in a use-dependent way (Dickie et al. 1992; Bliss and Collingridge 1993; Guevara-Guzman et al. 1994).

\section{VISUAL PLATFORM TASK}
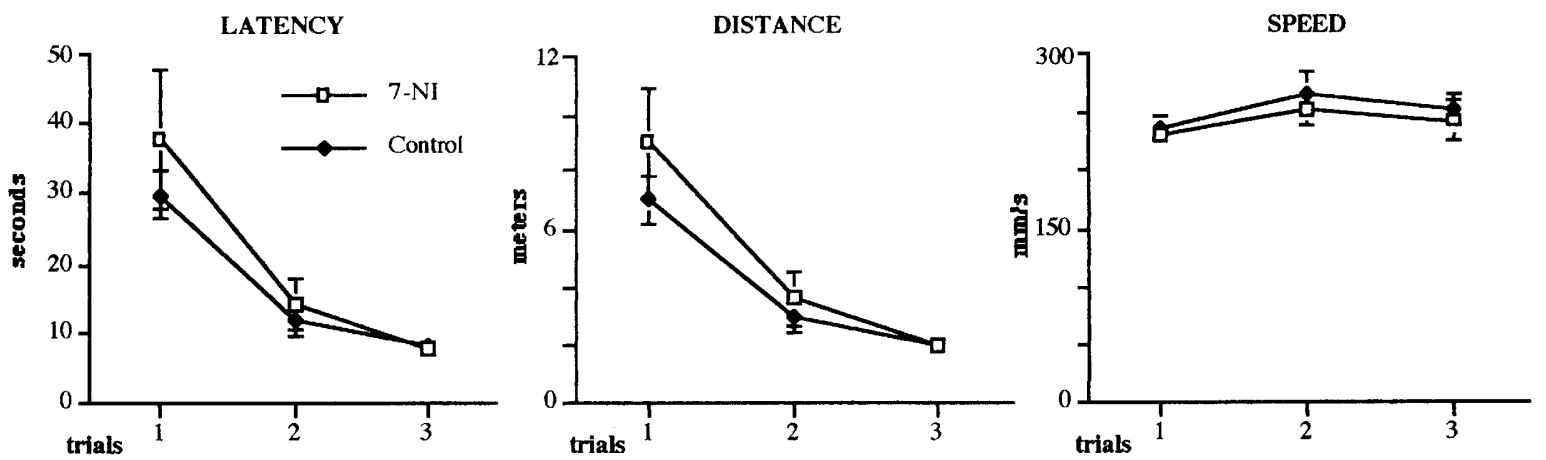

Figure 4: Visual platform task of animals, injected with $7-\mathrm{NI}(30 \mathrm{mg} / \mathrm{kg})$ i.p., $30 \mathrm{~min}$ before first trial compared to controls injected with vehicle. The platform in the pool was visible to the animals. Two-way ANOVA did not reveal a difference between treatments but showed significant differences between trials for latency $[F(2,84)=7.614, P<0.00001]$, and distance $[F(2,84)=8.212, P<0.00001]$ but not for speed.

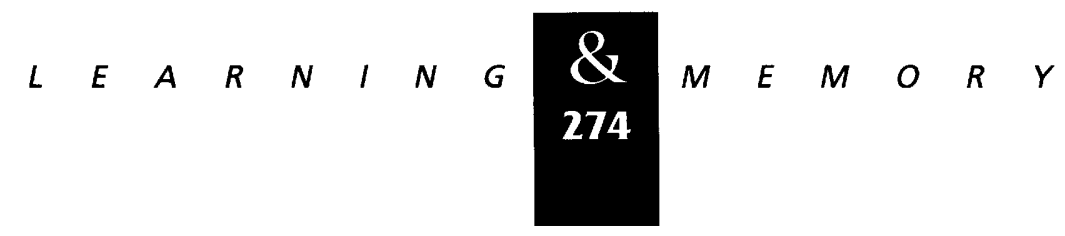


a)

8- ARM MAZE, LATENCY

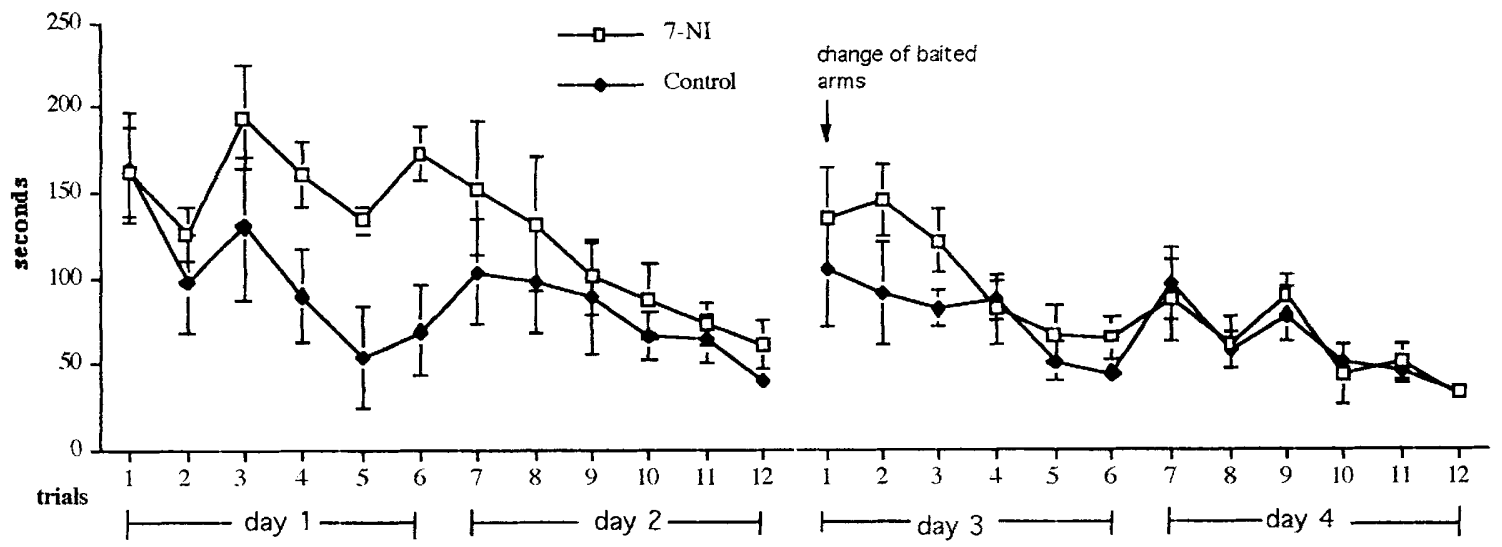

b)

WORKING MEMORY ERRORS
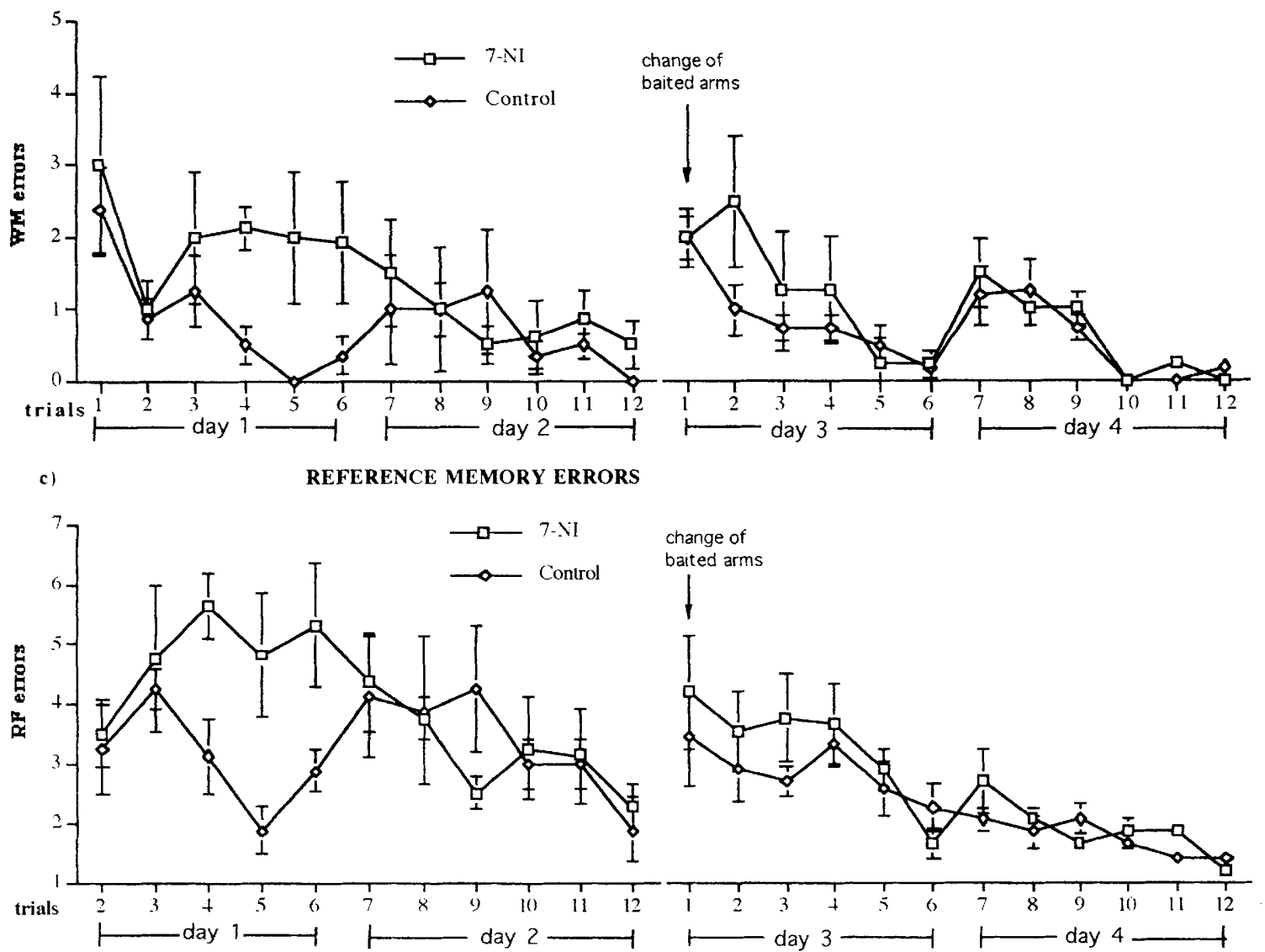

Figure 5: (a) Latency of rats injected with $7-\mathrm{NI}(30 \mathrm{mg} / \mathrm{kg})$ i.p., $30 \mathrm{~min}$ before first trial $(n=8)$ compared to controls $(n=8)$ injected with vehicle, learning the radial arm maze task. Three arms were baited. On day 3 , the locations of the baited arms were changed. Two-way ANOVA revealed difference on days 1 and 2 between trials $[F(11,168)=3.56, P<0.0001]$ and between treatments $[F(1,14)=14.87, P<0.0001]$. On days 3 and 4 ANOVA revealed a difference between trials only $[F(11,168)=2.56, P<0.001]$. (b) Working memory errors of animals learning the radial arm maze task. Two-way ANOVA revealed a difference on days 1 and 2 between trials $[F(11,168)=2.13, P<0.02]$ and between treatments $[F(1,14)=7.70$, $P<0.005]$. On days 3 and 4 , ANOVA revealed a difference between trials only $[F(11,168)=2.46, P<0.01]$. (c) Reference memory errors of animals learning the radial arm maze task. Two-way ANOVA revealed a difference on days 1 and 2 between trials $[F(10,154)=2.20, P<0.02]$ and between treatments $[F(1,14)=7.43, P<0.005]$. On days 3 and 4 , ANOVA revealed a difference between trials only $[F(11,168)=2.86, P<0.01]$.

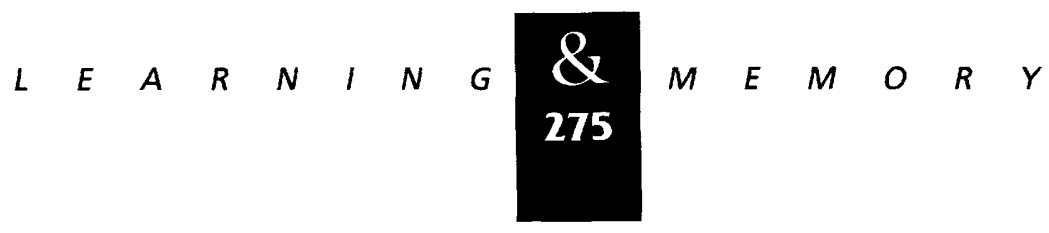


The same role had been allocated to arachidonic acid in previous investigations (Lynch et al. 1989; Zhang and Dorman 1993). Some investigations suggest that both messengers act in a collaborative fashion (O'Dell et al. 1991; Bliss and Collingridge 1993). Behavioral studies suggest that both messengers are involved in learning in the chick. NO is involved in the early phase of learning, whereas arachidonic acid plays a role in memory consolidation (Hölscher and Rose 1994; Hölscher 1995) and in learning in the rat where inhibitors of enzymes that release NO or arachidonic acid have an additive effect of impairing spatial learning (Hölscher et al. 1995). Hence, the transient amnesic effect of NOS inhibition in this study as well as in others can be explained in this way. Also, the contradictory results published from in vitro work in the role of NO in synaptic transmission can be explained with this mechanism.

Taken together, the evidence presented here and the results of Doyle et al. (1996), that 7-NI prevents induction of LTP of synaptic transmission in vivo, supports the interpretation that inhibition of NOS causes impairments in learning and memory formation.

\section{Acknowledgments}

This work has been supported by a grant from the European Community under the Human Capital and Mobility Scheme.

The publication costs of this article were defrayed in part by payment of page charges. This article must therefore be hereby marked "advertisement" in accordance with 18 USC section 1734 solely to indicate this fact.

\section{References}

Amir, S. 1992. Blocking NMDA receptors or nitric oxide production disrupts light transmission to the suprachiasmatic nucleus. Brain Res. 586: 336-339.

Babbedge, R.C., P.A. Blandward, S.L. Hart, and P.K. Moore. 1993. Inhibition of rat cerebellar nitric-oxide synthase by 7-nitro-indazole and related substituted indazoles. Br. J. Pharmacol. 110: 225-228.

Bannerman, D.M., P.F. Chapman, P.A.T. Kelly, S.P. Butcher, and R.G.M. Morris. 1994a. Inhibition of nitric-oxide synthase does not impair spatial learning. J. Neurosci. 14: 7404-7414.

Bannerman, D.M., S.P. Butcher, and R.G.M. Morris. 1994b. Intracerebroventricular injection of a nitric oxide synthase inhibitor does not affect long-term slope potentiation in vivo. Neuropharmacology 33: 1387-1397.

Bannerman, D.M., D.F. Chapman, P.A.T. Kelly, S.P.
Butcher, and R.G.M. Morris. 1994c. Inhibition of nitric oxide synthase does not inhibit the induction of long-term potentiation in vivo. J. Neurosci. 14: 7415-7425.

Bliss, T.V.P. and G.L. Collingridge. 1993. A synaptic model of memory: Long-term potentiation in the hippocampus. Nature 361: 31-39.

Böhme, G.A., C. Bon, J.-M. Stutzmann, A. Doble, and J.-C. Blanchard. 1991. Possible involvement of nitric oxide in long-term potentiation. Eur. J. Phamacol. 199: 379-381.

Böhme, G.A., C. Bon, M. Lemaire, M. Reibaud, O. Piot, J.-M. Stutzmann, A. Doble, and J.-C. Blanchard. 1993. Altered synaptic plasticity and memory formation in nitric oxide synthase inhibitor-treated rats. Proc. Natl. Acad. Sci. 90: 9191-9194.

Bon, C., G.A. Böhme, A. Doble, J.-M. Stutzmann, and J.-C. Blanchard. 1992. A role for nitric oxide in long-term potentiation. Eur. I. Neurosci. 4: 420-424.

Bredt, D.S. and S.H. Snyder. 1992. Nitric oxide, a novel neuronal messenger. Neuron 8: 3-11.

Butelman, E.R. 1990. The effect of NMDA antagonists in the radial arm maze task with and without interposed delay. Pharmacol. Biochem. \& Behav. 35: 533-536.

Buxton, L.O., D.J. Cheek, D. Echman, D.P. Westfall, K.M. Sanders, and K.D. Keef. 1993. $N^{G}$-nitro-L-arginine methyl ester and other alkyl esters of arginine are muscarinic receptor antagonists. Circ. Res. 72: 387-395.

Chapman, P.F., C.M. Atkins, M.T. Allen, J.E. Haley, and J.E. Steinmetz. 1992. Inhibition of nitric oxide synthesis impairs two different forms of learning. NeuroReport 3: 567-570.

Dickie, B.G.M., M.J. Lewis, and J.A. Davies. 1992. NMDA-induced release of nitric oxide potentiates aspartate overflow from cerebellar slices. Neurosci. Lett. 138: 145-148.

Dinerman, J.L., T.M. Dawson, M.J. Schell, and A. Snowman. 1994. Endothelial nitric oxide synthase localized to hippocampal pyramidal cells: Implications for synaptic plasticity. Proc. Natl. Acad. Sci. 91: 2414-2418.

Doyle, C., C. Hölscher, M.J. Rowman, and R. Anwyl. 1996. The selective neuronal nitric oxide synthase antagonist 7-nitro indazole blocks both long-term potentiation and depotentiation of field excitatory postsynaptic potentials in rat hippocampal CA1 in vivo. J. Neurosci. 16: 418-424.

Estall, L.B., S.J. Grant, and G.A. Cicala. 1993. Inhibition of nitric oxide (NO) production selectivity impairs learning and memory in the rat. Pharmacol. Biochem. Behav. 46: 659-962.

Guevara-Guzman, R., P.C. Emson, and K.M. Kendrick. 1994. Modulation of in vivo striatal transmitter release by nitric oxide and cyclic GMP J. Neurochem. 62: 807-810.

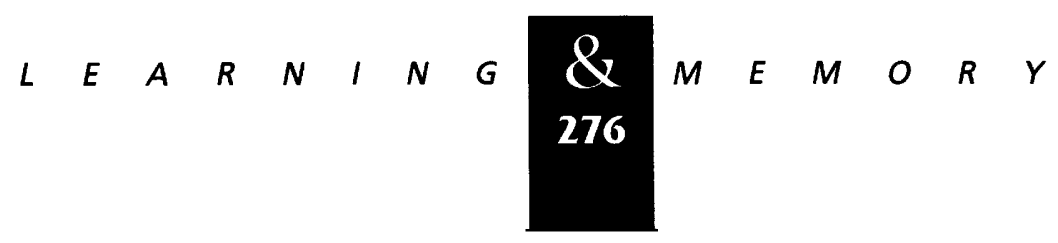


Hölscher, C. 1995. 7-Nitro indazole, a neuron specifoc nitric oxide synthase inhibitor, produces amnesia in the chick. Learning Memory 1: 9-11.

Hölscher, C. and S.P.R. Rose. 1992. An inhibitor of nitric oxide synthesis prevents memory formation in the chick. Neurosci. Lett. 145: 165-167.

1993. Inhibiting synthesis of the putative retrograde messenger nitric oxide results in amnesia in a passive avoidance task in the chick. Brain Res. 619: 189-194.

1994. Inhibitors of phospholipase $A_{2}$ produce amnesia for a passive avoidance task in the chick. Behav. Neural Biol. 61: 225-232.

Höscher, C., L. Canevari, and G. Richter-Levin. 1995. Inhibitors of $\mathrm{PLA}_{2}$ and NO synthase cooperate in producing amnesia of a spatial task. NeuroReport 6: 730-734.

Iga, Y., M. Yoshioka, H. Togashi, and H. Saito. 1993. Inhibitory action of $\mathrm{N}^{w}$-nitro-L-arginine methyl ester on in vivo long-term potentiation in the rat dentate gyrus. Eur. I. Pharmacol. 238: 395-398.

Jarrad, L.E. 1986. Selective hippocampal lesions and behavior. Implications for current research and theorizing. In The hippocampus (ed. W. Seifert), pp. 93-126. Plenum Press, New York, NY.

Kato, H., K. Kogure, Y. Liu, T. Araki, and Y. Itoyama. 1994. Induction of NADPH-diaphorase activity in the hippocampus in a rat model of cerebral ischemia and ischemic tolerance. Brain Res. 65 271-75.

Kilbourn, R.G. 1991. Regulation of nitric oxide biosynthesis: Cofactor requirement and enzymatic characteristics. 39th Forum in Immunology, Nitric Oxide and Host Defence. Res. Immunol. 142: 587-591.

Lot, T.Y., G. Stark, and V.G. Wilson. 1993. Endothelium-dependent contractions to $N^{G}$-nitro-L-arginine methyl ester in the porcine isolated splenic artery are sensitive to cyclooxygenase and lipoxygenase inhibitors. Naunyn-Schmiedebergs Arch. Pharmakol. 347: 115-118.

Lynch, M.A., M.L. Errington, and T.V.P. Bliss. 1989. Nordihydroguaiaretic acid blocks the synaptic component of long-term potentiation and the associated increases in release of glutamate and arachidonate: an in vivo study in the dentate gyrus of the rat. Neuroscience 30: 693-701.

Ma, L., Y. Ishizaki, I. Morita, and S. Murota. 1991. Presence of nitric oxide synthase activity in the neurons of the rat embryonal cerebrum. Neurosci. Lett. 132: 23-25.

MacKenzie, G.M., S. Rose, P.A. Blandward, P.K. Moore, P. Jenner, and C.D. Marsden. 1994. Time-course of inhibition of brain nitric-oxide synthase by 7-nitro indazole. NeuroReport 5: 1993-1996.

MCNaughton, N. 1993. Statistics for behavioural neuroscience. In Behavioural neuroscience: A practical approach (A. Sahgal), pp. 169-188. IRL Press, Oxford, UK.

Minc-Golomb, D. and J.P. Schwartz. 1994. Expression of constitutive nitric oxide synthase in a primary neuronal culture. NeuroReport 5: 1466-1468.

Mizutani, A., H. Saito, and K. Abe. 1993. Involvement of nitric oxide in long-term potentiation in the dentate gyrus in vivo. Brain Res. 605: 309-311.

Moncado, S. and R.M.J. Palmer. 1992. L-arginine: Nitric oxide pathway. Int. Soc. Appl. Cardiovasc. Biol. 2: 139-151.

Moore, P.K., R.C. Babbedge, P. Wallace, Z.A. Garren, and S.L. Hart. 1993a. 7-Nitro indazole, an inhibitor of nitric oxide synthase, exhibits anti-nociceptive activity in the mouse without increasing blood pressure. Br. I. Pharmacol. 108: $296-297$.

Moore, P.K., P. Wallace, Z. Gaffen, S.L. Hart, and R.C. Babbedge. 1993b. Characterization of the novel nitric-oxide synthase inhibitor 7-nitro indazole and related indazoles-Antinociceptive and coardiovasacular effects. $\mathrm{Br}$. J. Pharmacol. 110: 219-224.

Musleh, W.Y., K. Shahi, and M. Baudry. 1993. Further studies concerning the role of nitric oxide in LTP induction and maintenance. Synapse 13: 370-375.

Nathan, C. 1991. A commentary: inducible nitric oxide synthase. Res. Immunol. 142: 600-602.

Nowicky, A.V. and L. Bindman. 1993. The nitric oxide synthase inhibitor, $\mathrm{N}$-monomethyl-L-arginine blocks induction of a long-term potentiation-like phenomenon in rat medial frontal cortical neurons in vitro. J. Neurophysiol. 70: 1255-1259.

O'Dell, T.J., R.D. Hawkins, E.R. Kandel, and O. Arancio. 1991. Tests of the roles of two diffusible substances in long-term potentiation: evidence for nitric oxide as a possible early retrograde messenger. Proc. Natl. Acad. Sci. 88: $11285-11289$.

O'Dell, T.J., P.L. Huang, T.M. Dawson, J.L. Dinerman, S.H. Snyder, E.R. Kandel, and M.C. Fishman. 1994. Endothelial NOS and the blockade of LTP by NOS inhibitors in mice lacking neuronal NOS. Science 265: 542-546.

Ohno, M., M. Kikusui, A. Yoshimatsu, T. Yamamoto, and S. Watanabe. 1994. Somatostatin alleviates impairment of working memory induced by hippocampal muscarinic $M_{1}$ receptor blockade in rats. Eur. f. Pharmacol. 271: 557-560.

Olton, D.S., J.T. Becker, and G.E. Handelmann. 1979. Hippocampus, space and memory. Behav. Brain Sci. 2: 313-365.

Rasmussen, M., C.A. Barnes, and B.L. McNaughton. 1989. A systematic experiment of cognitive mapping, working memory and temporal discontiguity theories of hippocampal function. Psychobiology 17: 335-348.

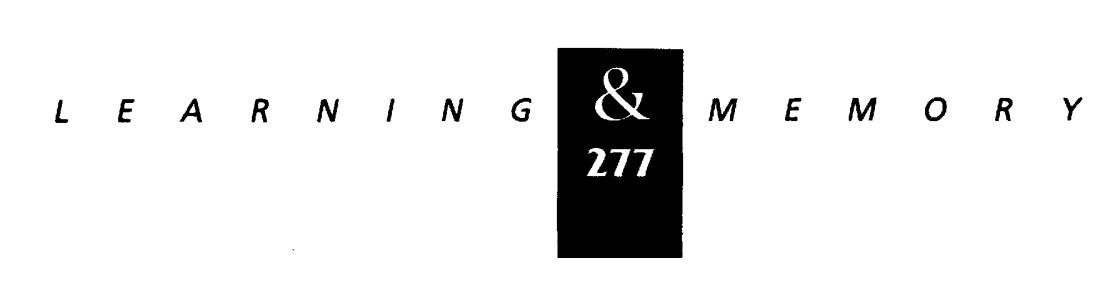


Hölscher et al.

Rees, D.D., R.M.J. Palmer, R. Schultz, H.F. Hodson, and S. Moncada. 1990. Characterization of three inhibitors of endothelial nitric oxide synthase in vitro and in vivo. Br. I. Pharmacol. 101: 746-752.

Saxon, D.W. and A.J. Beitz. 1994. Cerebellar injury induces NOS in Purkinje cells and cerebellar afferent neurons.

NeuroReport 5: 809-812.

Schmidt, H.H.H.W., J.S. Pollock, M. Nakane, U. Förstermann, and F. Murad. 1992.

$\mathrm{Ca}^{2+} /$ calmodulin-regulated nitric oxide synthases. Cell Calcium 13: 427-434.

Schuman, E.M. and D.V. Madison. 1991. A requirement for the intercellular messenger nitric oxide in long-term potentiation. Science 254: 1503-1506.

Snyder, S.H. and D.S. Bredt. 1992. Biological roles of nitric oxide. Sci. Am. 251: 28-35.

Tonkiss, J., J. Feldon, and J.N.P. Rawlins. 1990. Section of the descending columns of the fornix produces delay- and interference-dependent working memory deficits. Behav. Brain Res. 36: 113-126.

Vickroy, T.W. and W.L. Malphurs. 1995. Inhibition of nitric oxide synthase activity in cerebral cortical synaptosomes by nitric oxide donors: Evidence for feedback autoregulation. Neurochem. Res. 20: 299-304.

Vincent, S.R. and H. Kimura. 1992. Histochemical mapping of nitric oxide synthase in the rat brain. Neuroscience 46: 755-784.

Williams, J.H., M.L. Errington, Y.-G. Li, A. Nayak, K.P.S.J. Murphy, and T.V.P. Bliss. 1993. The supression of long-term potentiation in rat hippocampus by inhibitors of nitric oxide synthase is temperature and age dependent. Neuron 11: $877-884$.

Zhang, L. and R.V. Dorman. 1993. Synergistic potentiation of glutamate release by arachidonic acid and oleoyl-acetyl-glycerol. Brain Res. Bull. 32: 437-441.

Received November 2, 1995; accepted in revised form April 1, 1996. 


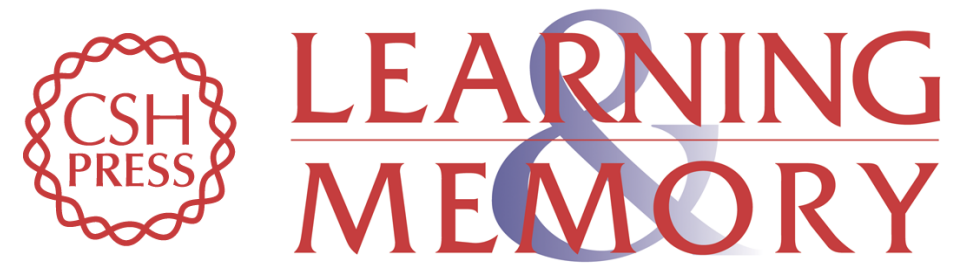

\section{7-Nitro indazole, a selective neuronal nitric oxide synthase inhibitor in vivo, impairs spatial learning in the rat.}

C Hölscher, L McGlinchey, R Anwyl, et al.

Learn. Mem. 1996, 2:

Access the most recent version at doi:10.1101//m.2.6.267

References This article cites 53 articles, 8 of which can be accessed free at: http://learnmem.cshlp.org/content/2/6/267.full.html\#ref-list-1

License

Email Alerting Receive free email alerts when new articles cite this article - sign up in the box at the Service top right corner of the article or click here. 